\title{
Las sisas sobre las bebidas alcohólicas y la asistencia espiritual de la Isla de León en el siglo XVIII ${ }^{1}$
}

\author{
Carlos Córcoles Cabello
}

\section{INTRODUCCIÓN}

Sin duda, se podría calificar de "renacimiento" el fenómeno experimentado por la Isla de León ${ }^{2}$ en el XVIII. En ese siglo, y de la mano de los Borbones, comenzaría su protagonismo como villa de acendrado carácter militar que aún perdura en nuestros días. Esa nueva entrada en la vida estuvo motivada por la ubicación en su término del Real Cuerpo de Marina y de unas actividades navales, cuya presencia convertiría a la isla en uno de los más señalados centros industriales del Setecientos. Sin embargo, la rápida transformación sufrida por el lugar dejaría al descubierto numerosas carencias asistenciales motivadas, principalmente, por la falta de recursos económicos y por la hostilidad e indiferencia mostrada por Cádiz ante el nuevo núcleo urbano que se estaba formando. De esta forma se hizo difícil hacer frente a la creación de la infraestructura precisa para atender al incesante incremento del vecindario en el período 17291755 , tiempo en el cual la isla perteneció a la jurisdicción gaditana ${ }^{3}$. Una de estas carencias, quizás la más llamativa, pertenecía al ámbito religioso, pues esa isla dieciochesca no dispondría de un edificio parroquial capaz de acoger con holgura a los fieles hasta bien superada la mitad del siglo, cuando el número de habitantes era ya considerable.

\footnotetext{
Este artículo es parte del trabajo de investigación defendido por el autor en la sede de la UNED, bajo la dirección del Dr. Don Juan Antonio Sánchez Belén.

${ }^{2}$ Isla de León o Real Isla de León era el nombre recibido por la actual San Fernando hasta

3 La Isla de León dejó de pertenecer a la Casa Ducal de Arcos en 1729 cuando Felipe $V$ la incorporó a la Corona. A partir de entonces pasó a estar bajo la tutela de Cádiz hasta 1766, año en el cual un Real Despacho instituía el primer ayuntamiento autónomo isleño.
} 1813. 
En efecto, la falta de medios económicos impidió durante demasiado tiempo la construcción de un nuevo templo apropiado a las necesidades de la época. En ello influyeron determinantemente varias peculiaridades isleñas de ese tiempo como era, por ejemplo, la no disponibilidad por parte de la iglesia isleña de beneficio alguno en el capítulo de diezmos. Por otro lado, los ingresos de fábrica de la antigua y reducida parroquia eran tan cortos que ni siquiera se cubrían los gastos más corrientes. Así las cosas, y como localmente no se podía disponer de capital alguno, la imprescindible fuente de financiación para una obra de tan alto costo como la pretendida, sólo podía proceder de instancias ajenas al mundo de la Iglesia, como efectivamente sucedió.

A petición del obispo de Cádiz ${ }^{4}$, gran valedor de la causa isleña, el Consejo de Castilla reasignaría el producto de unas sisas sobre las bebidas alcohólicas - vigentes en la isla por motivos fiscales- a la edificación de un templo parroquial. Con el paso del tiempo, estas sisas no sólo servirían para costear el edificio eclesial, sus modificaciones y los importantes reparos necesitados a los pocos años de su puesta en servicio, sino también para el mantenimiento del culto y del clero, la construcción de un cementerio acorde con el vasto vecindario y el sostenimiento de un importante horfanato. Se podría afirmar, por tanto, que, indirectamente, el consumo de bebidas alcohólicas sirvió para dotar y mantener la infraestructura religiosa diocesana en la Isla de León durante el dilatadísimo período de sesenta y un años, tiempo de vigencia de los arbitrios ${ }^{5}$. Posiblemente, el caso haya sido único en la España del Antiguo Régimen, no por el tipo de impuesto en sí -frecuentemente usado en nuestro país para diversos fines- sino por su longevidad y por el objeto único de su aplicación.

\section{LAS SISAS SOBRE LAS BEBIDAS ALCOHÓLICAS}

Las circunstancias de partida hacia el extraordinario desarrollo urbano y poblacional que experimentó la Isla de León en el siglo xvIII no pudieron ser más adversas. Lo infructífero de las tres cuartas partes de las tierras de su reducido término, apenas treinta kilómetros cuadrados, y la increíble falta de interés de los isleños por los trabajos agrícolas, hizo que el progreso del sector primario se mantuviera en un plano de escasa relevan1776.

4 Fray Tomás del Valle. Promovido a la sede de Cádiz en 1730 y fallecido en la misma en

5 Los arbitrios o sisas que se citan se aplicaron en la Isla de León desde 1757 hasta 1818. 
cia ${ }^{6}$. Algo tuvo que ver con esta situación la apatía de la Casa Ducal de Arcos, señora y dueña del lugar desde el siglo xv, de quien no se podía esperar ninguna acción colonizadora en favor de la isla como haría el acaudalado Domingo López de Carvajal con la «nueva población» de Algar en la sierra de Cádiz ${ }^{7}$. Por el contrario, los Arcos deseaban deshacerse del yermo territorio traspasándolo a la ciudad de Cádiz -interesada en la adquisición- como se intentó en 1727, aunque la transacción no llegaría a culminarse ${ }^{8}$. Sin embargo, este despego por la Isla de León se trocaría en furioso celo por la propiedad en el momento que Felipe $\mathrm{V}$ la incorporó a la Corona en 1729, a tan sólo dos años de la fallida venta. A raíz de la decisión real, la casa ducal emprendió acciones judiciales en su contra y el Consejo de Castilla hubo de devolver y ratificar todos los dominios territoriales anteriores en sendas disposiciones fechadas en 1732 y $1743^{\circ}$. Como consecuencia, para la Corona quedaron solamente los derechos jurisdiccionales.

Si la casa de Arcos no promovió ninguna mejora en la isla, Cádiz no le fue a la zaga. Desde antiguo, la importante ciudad pareció interesada en abortar cualquier progreso isleño y en este sentido se entienden los severos castigos previstos para aquellos que osasen construir casas en la Isla de León con el ánimo de habitarlas permanentemente ${ }^{10}$. Por supuesto, las prohibiciones no eran de aplicación a los poderosos de la ciudad quienes pudieron ir construyendo sus fincas de recreo -las caserías- sin inconveniente legal alguno. Cuando en 1729 la isla pasó de señorial a realenga y entró a formar parte de la jurisdicción gaditana, la capital se apresuró a desempolvar las restrictivas regulaciones ante el auge poblacional que, aunque mínimo, ya se estaba observando como resultado del inicio de las obras del Arsenal de la Carraca ".

Estos fueron los dos motivos principales causantes del débil desarrollo presentado por la Isla de León al iniciarse el siglo XVIII: por un lado, la inercia secular de la oligarquía nobiliar y por otro, el egoísta proteccio-

- A.G.S. (Archivo General de Simancas). Catastro de Ensenada. Respuestas generales. Libro 562. Al reseñar en 1752 las medidas de las tierras en la Isla de León, de 5.319 aranzadas existentes, 4.000 fueron presentadas como infructíferas debido "a la naturaleza y a la desidia"

Carrero Galofre, R. y Gutiérrez Garcia, J.M., Algar. Cádiz 1983, págs. 44-48.

- Clavijo y Clavijo, S., La ciudad de San Fernando. San Fernando 1961, Tomo I, pág. 247.

a Caistelly, J., Ligeros apuntes históricos y colección de citas, documentos y datos estadísticos de la ciudad de San Fernando. Desde los tiempos más remotos hasta 1825. San Fernando 1891. Doc. número 60, pág. 247.

10 Clavijo y Clavijo, S., Opus cit, pág. 251. Reales Cédulas fechadas en 1651 y 1696.

1" Barros Caneda, J.R., Arquitectura y urbanismo en la Carraca durante el siglo Xvil. Sevilla 1989, pág. 21. 
nismo desplegado por Cádiz. No es de extrañar que, ante estas circunstancias, la isla encontrase grandes problemas en su evolución a causa de la carencia absoluta de infraestructuras sobre las que apoyar el espectacular desenvolvimiento urbano y poblacional. El hecho se debió a la ausencia de acciones previsoras ante el desarrollo del pueblo, pues los gaditanos vieron en la isla a una rival y se inhibieron por completo de ayudarla. Por otro lado, la decisión de Felipe $V$ de incorporar la Isla de León a la Corona hubiera sido del todo positiva de no haberse truncado por las rectificaciones posteriores en favor de la casa ducal. Al no ser así, el futuro de la isla quedó maniatado: el ayuntamiento nacido en 1766 dispondría de "arbitrios" pero nunca de "propios", con lo cual las perspectivas económicas locales quedarian muy limitadas.

De hecho, la Villa llegó a ser uno de los lugares más caros de los alrededores debido, desde luego, a la presencia de los militares, aunque también a la reiterada sobrecarga impositiva de algunos artículos de gran consumo por parte del pueblo, pues tanto el Consejo de Castilla como las autoridades civiles y eclesiásticas no encontraron otras vías de financiación para sus proyectos y necesidades. La ausencia de esas estructuras previas tan necesarias para soportar a una población que crecería sin cesar alrededor del Real Cuerpo de Marina, intentó ser paliada por las autoridades locales ahorrando todo lo posible con vistas a realizar las obras públicas necesarias en el término municipal. Pero los resultados no fueron siempre los apetecidos y por una razón u otra no se alcanzó nunca la cota de servicios exigidos por la Villa, ni siquiera en el plano religioso.

No obstante, la diócesis trató de colocarse a la altura de las circunstancias y consiguió, más mal que bien, erigir un templo parroquial acorde con las necesidades en un plazo razonable de tiempo. El obispo de Cádiz, resuelto a solventar el problema de la asistencia espiritual, encontró relativamente pronto una vía para poder financiar la construcción de una nueva iglesia con capacidad suficiente para atender al creciente vecindario. Para ello aprovecharia la existencia de unos arbitrios sobre las bebidas alcohólicas establecidos con anterioridad en la Isla de León. Con el tiempo, la vigencia de esas tasas impositivas resultaría fundamental para el desarrollo de muchos aspectos de la Villa isleña a lo largo del XVIII, especialmente los relacionados con la vida religiosa, el clero y la caridad. Estos arbitrios no consistieron tan sólo en un impuesto o sisa, tal y como se le ha llamado -y se le llama comúnmente-, sino en dos perfectamente delimitados y con orígenes distintos en el tiempo. Eso sí, ambos nacieron por una motivación análoga: la ausencia de recursos propios en la isla para satisfacer sus deudas oficiales con el Consejo de Castilla durante el período de tutela gaditana. La primera vez que se implantó una tasa de esas características fue a finales de 1749 con motivo 
de la «única contribución» a causa de la insolvencia isleña para hacer frente a un débito producido por la mala administración de la renta de aguardiente ${ }^{12}$. Ante la deuda, que ascendía a 26.266 reales y 7 maravedís de vellón, no se encontró otra salida que gravar algún tipo de abasto, prefiriéndose cargar con cuatro maravedís cada cuartillo de aguardiente consumido en la isla ${ }^{13}$ antes de repartir semejante cantidad entre el, aún escaso, vecindario ${ }^{14}$. De esta manera se establecía un camino para extinguir la deuda - aunque fuera a largo plazo - sin causar grandes perjuicios al pueblo. A nadie pareció importarle que se tardasen casi siete años en pagar lo debido.

El segundo arbitrio se impuso en 1756, cuando al primero todavía le faltaban unos meses para lograr su cancelación. En esta oportunidad el motivo que originó la nueva sisa fue el pago de los gastos producidos por la extinción de una plaga de langosta que asoló los campos del Reino de Sevilla en el año próximo anterior de 1755. Una vez efectuado el consabido reparto entre las ciudades y pueblos por la intendencia hispalense, a la Isla de León le quedó asignada una cuota por la cantidad de 6.667 reales y 23 maravedís ${ }^{15}$. La cifra resultaba mucho menor a la de la deuda de 1749, pero al igual que en el otro caso, tampoco existía un fondo de dónde satisfacerla. Al llegar la noticia del reparto a la Real Villa en mayo de 1756, el recién nombrado primer alcalde mayor ${ }^{16}$ quedó angustiado por varias razones. La primera por la imposición en si misma, pues era considerada completamente injusta en vista de la minúscula significación de los cultivos agrícolas de la isla ${ }^{17}$. Otro motivo de preocupación era el no poseer la isla fondo oficial alguno capaz de amortizar la deuda, lo que obligaba - al no quedar otra salida - a un reparto entre la población pechera del pueblo. Pero a este límite no quería llegar el alcalde, pues se cometería una injusticia mayor aún al ser bastante corto el número de menestrales $y$, por tanto, muy alta la carga resultante por familia. La tercera razón, quizás la más exasperante, era la escasa probabilidad de

12 A.G.S., Castro de Ensenada. Respuestas generales. Libro 562. Al hacerse referencia al arbitrio vigente en la Isla en 1752 , se reseñó que su origen vino motivado por un descubierto en la administración del aguardiente y licores afines.

13 A.D.C., (Archivo Diocesano de Cádiz). Secretaría de Cámara. Leg. 22.

14 A.G.S., Castro de Ensenada. Respuestas generales. Libro 562 . En 1752 el número de vecinos era de seiscientos cincuenta. En 1749 la cifra debió ser menor.

${ }_{15}$ A.M.S.F., Varios: Iglesia. Leg. 2.392. Comunicación de la Intendencia de Sevilla del 24IV-1756.

16 A.M.S.F., Varios: Iglesia. Leg. 2.392. Para facilitar la gobernabilidad de la Isla de León, en 1755 se nombró un alcalde mayor, Don Nicolás de Egea, aún dependiente de Cádiz.

17 Molina Martínez, J.M., San Fernando, demografía y sociedad (1656-1750). San Fernando 1992, págs. 107-108. 
hacer comprender al Consejo de Castilla la arbitrariedad cometida con la Isla de León. No extraña, por tanto, que el alcalde mayor fuera capaz de ofrecer una cierta resistencia a los mandatos del intendente de Sevilla, aunque al final hubiera de sucumbir ante las demandas del gobernador del Supremo Consejo, fray Diego de Rojas y Contreras, obispo de Cartagena, quien, por cierto, se convertiría a los pocos meses en personaje fundamental para la resolución del problema espiritual de la Isla de León, al facilitar todo lo concerniente a la financiación de una nueva iglesia parroquial.

Las instrucciones emanadas del intendente ${ }^{18}$ contemplaban, respecto al pago de la deuda, cuatro fuentes para obtener el capital a abonar, a saber:

1. Los sobrantes del caudal de propios, una vez satisfechas las deudas con los acreedores.

2. ${ }^{\circ} \mathrm{Si}$ el débito no quedaba cancelado con el fondo de propios, se dividiría el resto en diez partes, siendo sufragada una de ellas por los partícipes en los diezmos.

3. Las nueve proporciones restantes se reducirían a tres, de las cuales, dos se cargarian a los hacendados en tierras, olivares, viñas y ganados.

4. La tercera parte sobrante se repartiría entre los demás vecinos, menestrales y comerciantes, excluyendo a los pobres.

La cuestión a resolver radicaba en lo siguiente: la isla no disponía de propios y el único arbitrio conocido era el vigente sobre los licores que sisaba cuatro maravedís de cada cuartillo de aguardiente y bebidas afines. Como consecuencia, al no existir ingreso alguno en el capítulo de propios, la primera vía de pago establecida por el intendente no tenía aplicación, por lo cual la cantidad íntegra del reparto habría de recaer sobre el resto de los supuestos citados en el documento del asistente sevillano. Pero de la recaudación de los diezmos, ni un maravedí quedaba disponible en la isla, pues la parcelación en sesmos de este ingreso se hacía de la siguiente manera: tres partes para el rey, una para el cabildo catedralicio, una al beneficio de la iglesia y una al obispo ${ }^{19}$. Como se ve, el segundo supuesto tampoco se adaptaba a la isla. Lo peor fue que al tercero le ocurrió lo mismo, pues tampoco existían «haciendas de campo, ni cortijos, hazos, ganados, olivares, ni más viñas que las que posee el convento de

18 A.M.S.F., Varios: Ig/esia. Leg. 2.392.

19 A.D.C., Secretaria de Cámara. Leg. 22. Representación del obispo al Consejo de Castilla del 11-V-1764. 
San Agustín de Cádiz y la que goza Don Manuel de Arriaga», según uno de los testimonios aportados por el alcalde mayor en el informe remitido al Consejo de Castilla ${ }^{20}$.

En efecto, ante el cariz tomado por la situación, el alcalde mayor consideró oportuno presentar al Consejo las declaraciones de varias personas relevantes de la Villa, buscando cambiar la decisión del Tribunal sobre el repartimiento y así se decidió en cabildo. Testificaron el beneficiado de la iglesia, el juez delegado de la jurisdicción de Marina, el notario de la vicaría, el teniente de visitador de rentas provinciales y un contador de las mismas, coincidiendo todos en sus afirmaciones con el testimonio anterior. El escribano público, por su parte, dio fe del asunto principal: «El Consejo no ha señalado propios ni arbitrios alguno (para la Isla de León), fuera del citado de la renta del aguardiente" ${ }^{21}$. Así pues, y según el camino tomado por el asunto, sólo quedaban los habitantes de la Villa como hipotéticos pagadores de la deuda. Pero ocurría que el corto vecindario se componía, principalmente, de trabajadores de los Reales Arsenales de la Carraca y puente Zuazo y de marineros matriculados, de los cuales - según los declarantes-sólo algunos poseían la casa en la que habitaban como máximo bien material. En otro mundo aparte quedaban las villas de recreo de los gaditanos ricos, cuyas huertas, en palabras del alcalde mayor, "sirven más a lo deleitable que a lo útil» y no deberían ser tenidas en cuenta a efectos fiscales ${ }^{22}$.

Todo lo anterior fue recogido en la misiva enviada por el alcalde al gobernador del Consejo, en cuyo contenido se llegó a pedir: «se tílde y se borre la citada cantidad que se ha repartido a esta Islan ${ }^{23}$. El obispo de Cartagena contestó inmediatamente indicando se repartiera el débito entre la población y los abastos, al no haber hacendados. La réplica del alcalde insistiendo en sus posiciones hizo perder rigidez a la firmeza inicial de fray Diego de Rojas, tornándose un poco más tolerante en sus demandas. Había que pagar, sí, pero ues usted el que ha de repartir el importe que se ejecuta, cargando lo que le parezca en los abastos, dejando libre el del aceite por ser alimento" ${ }^{24}$. De esta manera, el alcalde dispuso de una mayor capacidad de maniobra y por ello, aprovechando la ocasión, no dudó en promulgar un auto el siete de agosto de ese año de 1756 , mediante el cual quedaba establecido un nuevo arbitrio que

20 A.M.S.F., Varios: Iglesia. Leg. 2.392. Informe del alcalde mayor al Consejo del 29-V-1756.

A.M.S.F., Ibidem.

22 Ibidem. Informe del alcalde mayor al Consejo del 9-VI-1756.

23 Ibidem.

${ }^{24}$ Ibidem. Gobernador del Consejo a alcalde mayor, 26-VII-1756. 
encarecía forzosamente los abastos, al no existir otra alternativa. Al menos, el pueblo parecía quedar exento de una contribución directa por repartimiento. Pero los isleños también se verían libres de ver sobrecargados los precios de sus alimentos cotidianos, pues de todos los abastos se eligió el del vino para sufrir por entero la deuda debida a la plaga de langosta. El alcalde recordaba, sin duda, el precedente del impuesto sobre el aguardiente aún en vigor. Pero él tenía, además, razones propias para escoger el vino: la primera, la rapidez con que se podía efectuar la recaudación debido al sencillo método necesario para llevarlo a cabo, la segunda, por ser un artículo considerado como no necesario y la tercera a una apreciación puramente personal: «porque su consumo se debe, por lo general, a gente viciosa ${ }^{25}$,. La medida en si misma no era del todo original, pues en esa España del Antiguo Régimen se contaba con numerosos ejemplos de imposiciones análogas, tanto anteriores como posteriores a la decisión del alcalde mayor de la Isla de León ${ }^{26}$. Lo insólito en el caso isleño sería el largo tiempo de vigencia de tal tipo de impuestos ${ }^{27}$.

El nuevo arbitrio sobre el vino entró en vigor a mediados del mes de agosto de 1756 y estuvo vigente solamente seis meses, es decir, hasta enero de 1757. El sistema establecido en un principio de sisar un real por arroba de vino encontró el rechazo del gremio de los montañeses, expendedores al por menor de bebidas en la Isla ${ }^{28}$, pues lo consideraban abusivo al gravar por igual vino de diferentes precios. Además, presentaba grandes dificultades para fraccionar el cobro en las medidas habituales de venta, como era el cuartillo. Consecuentemente, y con la intención de evitar males mayores con el, entonces, tan desabrido gremio ${ }^{29}$, se decidió sisar dos cuartillos por cada arroba de vino, independientemente de su calidad y precio. El encargado de la administración de este arbitrio fue el contador de la renta de millones en la Isla de León, cuyas misiones principales consistían en certificar mensualmente las arrobas de vino entradas en la villa y llevar la contabilidad de las rentas de dicho impuesto.

25 Ibidem. Auto del alcaide mayor fechado el 7-VIII-1756.

26 Dominguez Ortiz, A., Sociedad y Estado en el siglo XVIII Español. Barcelona 1988, págs. 75 y 299. A.M.P.R. (Archivo municipal de Puerto Real) Actas Capitulares. Año 1779. Se gravan las bebidas para la construcción de una conducción de agua dulce.

27 Una vez reimpuestas, las sisas sobre las bebidas alcohólicas estarían vigentes desde 1757 a 1818 bajo el nombre de "Arbitrio para la construcción de la iglesia parroquial».

28 A.G.S. Castro de Ensenada. Respuestas generales. Libro 562 . En 1752 existían en la Isla de León veintiuna tiendas de comestibles y diecinueve tabernas.

${ }_{29}$ Iglesias Rodríguez, J.J., Una ciudad mercantil en el siglo xvil: El Puerto de Santa Maria. Granada 1991, pág. 461 
Los gastos originados en la operación recaudatoria fueron de escasa cuantía y ascendieron tan sólo a seiscientos setenta y un real, que sirvieron, entre otros aspectos, para la compra de medidas sisadas y para abonar una cantidad del tres por ciento como tarifa por la cobranza del arbitrio. En enero de 1757 ya se contaba con 6.959 reales y 9 maravedís, cantidad suficiente para cancelar la deuda. En razón de ello, el alcalde mayor suspendió la vigencia del arbitrio desde el inicio del siguiente mes de febrero, anunciando al gremio de montañeses la aplicación de multas de cuatro ducados para aquellos taberneros que siguieran aplicando la sisa por su cuenta y en su propio beneficio ${ }^{30}$.

Sorprendentemente $-y$ sin causas conocidas- el concejo isleño no canceló la deuda con la intendencia de Sevilla de un modo inmediato, sino siete meses más tarde y porque se recibió una severa conminación oficial al respecto. El recibo de las Arcas Reales quedó fechado el treinta de septiembre de $1757^{31}$.

\section{LA REIMPOSICIÓN DE LAS SISAS}

Los dos arbitrios citados se implantaron de nuevo semanas más tarde - para disgusto de los bebedores - pasando a ser el soporte financiero de la construcción de una nueva iglesia parroquial, ya imprescindible para atender el tan crecido número de habitantes existentes a mitad del siglo XVIII.

En efecto, el aumento poblacional provocado en la Isla de León por las actividades navales sería de extraordinaria importancia. En relativamente poco tiempo, el tradicional paisaje mostrado por el "otrora Logar de la Puente", cambió sensiblemente a medida que tomaba cuerpo el proyecto de arsenales militares, pensado y llevado a cabo en una primera fase por Patiño y relanzado con fuerza años más tarde por Ensenada ${ }^{32}$. Después, superado en dos decenios el ecuador del siglo, llegaría el traslado del Real Cuerpo de Marina de Cádiz a la isla, con lo cual aquella balbuciente aldea de finales del diecisiete y principios del dieciocho se convirtió en una pujante villa llena de vida. Estos acontecimientos, la construcción del Arsenal de la Carraca por un lado y la llegada de miles de militares por el otro, marcan de manera diáfana las tres fases principales del crecimiento poblacional de la Isla de León ${ }^{33}$.

\footnotetext{
A.M.S.F., Varios: Iglesia. Leg. 2.392. Auto del alcalde mayor del 31-1-1757. Ibidem.

Barros Caneda, J.R., Opus cit., págs. 20-21.

33 En una primera fase, la población aumenta en razón del inicio de las obras del Arsenal
} 
A causa de la falta de infraestructuras, la isla se encontró con graves carencias muy difíciles de subsanar y lo arcaico permaneció demasiado tiempo instalado en la vilia. El no poseer ingresos fijos en el capítulo de propios para realizar aquellas obras municipales consideradas esenciales para el desarrollo y gobierno del pueblo, llevaron a situaciones completamente desfasadas y desacordes con la cantidad de gentes que hacían de la isla su residencia. Así, por ejemplo, las casas consistoriales no se iniciaron hasta bien avanzado el siglo $-y$ se concluirian casi en los albores del $x x-y$ por ello, alcaldes y regidores hubieron de celebrar los cabildos en las viviendas particulares de los primeros durante muchos años. Por otro lado, el sistema de abastecimientos era tan precario que, a la mínima dificultad, la población corría graves riesgos de pasar hambre, como ocurrió más de una vez ${ }^{34}$.

Un caso mucho más claro de la persistencia de esa estructura arcaica, la tenemos en algo tan fundamental para la época como era la asistencia espiritual del pueblo. En 1750, cuando era del todo obvio el aumento del número de habitantes, la diócesis seguía manteniendo en calidad de parroquia a una minúscula capilla ubicada en el interior del castillo señorial de los Arcos. El sagrado recinto habría sido suficiente, quizá, para esos hipotéticos trescientos vecinos citados por fray Gerónimo de la Concepción para el último cuarto del siglo anterior, pero incapaz para los seiscientos cincuenta de mitad del dieciocho. $Y$ todavía quedaban por llegar los dos empujes principales del desarrollo de la población isleña. El primero sería inmediato, en 1752, al impulsarse definitivamente hacia su finalización el iniciado, pero aletargado, proyecto del Arsenal de la Carraca. El segundo, todavía a cierta distancia en el tiempo, sería el citado traslado de la Marina en 1769.

de la Carraca y del incremento de las actividades industriales del llamado "Arsenal del Puente Zuazon. Este período llega hasta la mitad del siglo y en él los vecinos pasan de los trescientos citados por fray Gerónimo de la Concepción, a los seiscientos cincuenta reseñados en el catastro de Ensenada. La segunda fase se inició con el relanzamiento de los arsenales propiciado por Ensenada, cuya consecuencia sería alcanzar los mil seiscientos vecinos en 1764 (PONSOT, P., Atlas de Historia Económica de la Baja Andalucía. Siglos XVI-XIX. Sevilla 1986. Cuadro 10, pág. 110). El tercer "empuje» vendría originado por la llegada del Real Cuerpo de Marina en 1769, que incrementaría, en cuestión de días, en más de dieciséis mil personas la población isleña (Blanca Carlier, J.M., La Marina en Cádiz. Cádiz 1987, pág. 93). Pocos años después en 1775, el sindico personero cifraba en veintidós mil el número de habitantes en la Isla de León (A.M.S.F. Actas Capitulares. Libro 10. Sesión del 28-1-1775).

34 A.M.S.F. Actas Capitulares. Libro 8, 14, 15, 16, 17, 18, 32 y 35 . El deficiente sistema abastecedor de grano a la Isla de León y la ausencia de pósito, perjudicaron al pueblo isleño cada vez que se produjo alguna falta en el suministro de trigo debido a las malas cosechas, las guerras y las epidemias. En este aspecto, fueron de singular importancia las carencias de los años, $1773,1779,1783,1797$ y 1800. 
El obispo de la diócesis, fray Tomás del Valle, consciente del cambio experimentado en la isla con motivo de la constante llegada de gentes atraídas por la oferta de trabajo del Arsenal, decidió iniciar la construcción de un nuevo templo a pesar de no contar con ningún tipo de caudal permanente garantizador del éxito de la idea. En vista de no disponerse de la producción de los diezmos, ni de ningún otro tipo de ingreso fijo, solamente quedaba como único fondo susceptible de ser usado para financiar la obra, el de los beneficios de la fábrica de la vieja parroquia del castillo de los Arcos. Pero sus cortísimos ingresos eran superados casi siempre por los gastos, y, por tanto, el déficit aparecía año tras año como algo endémico. La pobreza de esta parroquia era tal, que el gasto efectuado en la adquisición de algo tan fundamental como vino y hostias, hubo de ser sufragado por las cofradías en más de una ocasión ${ }^{35}$. Pero el prelado no se arredró $y$, ante lo urgente de la situación espiritual de la isla, las obras se iniciaron con el concurso de las limosnas de varios particulares y las sustanciosas aportaciones hechas por el obispo de su propio pecunio. Es innecesario decir que el loable plan obtuvo, pasado poco tiempo, un fracaso absoluto, pues una obra de tal envergadura no podía depender de la ocasionalidad de las limosnas, ni de las donaciones de Valle, pronto obligadas a disminuir ante la presión estatal sobre las rentas de la Iglesia ${ }^{36}$.

Ante el estancamiento de la cuestión era necesario buscar forzosamente una vía para solucionar el tema de la asistencia espiritual y la única encontrada fue pedir ayuda a la Corona. Para ello, fray Tomás del Valle se dirigió al Consejo de Castilla en julio de 1756 exponiendo las importantes razones que le asistían para erigir una nueva iglesia parroquial, sugiriendo a la vez el camino para la financiación de la misma. La única forma de conseguirlo era la prorrogación del arbitrio del aguardiente, impuesto en 1749 y próximo a concluir, por el tiempo que durasen las obras, aduciendo el prelado "no ser este gravamen perjudicial en nada al común $y$, aunque lo fuera, su cortedad, que apenas llega a cinco o seis mil reales, les haría a los contribuyentes llevadera la pensión" ${ }^{37}$. Pocos meses más tarde, en diciembre, el obispo reconsideró su petición e incluyó también la sisa sobre el vino cuando aún estaba en vigor para el asunto de la langosta. Las prisas por asegurarse esta segunda sisa se comprende en vista del costo estimado para las obras de la nueva parroquia, oscilante

\footnotetext{
35 A.D.C., Secretaría de Cámara. Leg. 22. Carta del obispo al Consejo del 11-V-1764.

36 Ibidem. Las rentas de la mitra ascendian a 18.000 ducados, pero 8.000 se destinaban a excusados, perpetuas pensiones, subsidios y costas para recolección de frutos.

37 Ibidem. Carta del obispo al Consejo del 30-V11-1756.
} 
entre los veinticinco y treinta mil pesos, "cantidad imposible de obtener de la sisa de cuatro maravedís en cada cuartillo de aguardiente» ${ }^{38}$. El Consejo, tras referirse a diversas cuestiones rutinarias, y preguntar si no había otro camino menos perjudicial para el pueblo, accedió a las pretensiones del obispo con la promulgación de un Real Despacho fechado el veintidós de marzo de 1757 , en donde se señalaba como fuente financiadora de las obras de la iglesia los citados arbitrios del aguardiente y el del vino, abolidos por el alcalde mayor de la Isla el uno de febrero del mismo año, es decir, tan sólo unas semanas antes de la aparición del despacho real.

El despacho de Fernando $\mathrm{VI}^{39}$, dirigido tanto al obispo de Cádiz como a la justicia ordinaria de la Isla de León, contenía en esencia cuatro puntos fundamentales:

$11^{\circ}$ Se concedía a la Isla de León la continuación de los arbitrios de dos cuartillos de sisa en arroba de vino y el del aguardiente por un tiempo de diez años «menos el que no se necesite».

2. El producto de los arbitrios se aplicaría en las obras exteriores e interiores de la iglesia.

3. El empleo de los caudales correría a cargo de las personas elegidas por el obispo, aunque con la intervención de la justicia civil para la mejor recaudación de los impuestos.

$4 .^{\circ}$ Se precisaba como necesario que el obispo diera cuenta todos los años del producto de los arbitrios, así como de su inversión y del estado de las obras con el objeto de cancelar las dos sisas en cuanto las obras estuvieran concluidas.

El 3 de abril de ese año de 1757 se leyó el Real Despacho en la Isla de León, ordenando el alcalde mayor que a partir del día dieciséis entraran otra vez en vigor ambos impuestos. Al mismo tiempo, y sabiendo la resistencia del gremio de los montañeses a este tipo de sisas - no sólo por el consecuente encarecimiento de las bebidas, sino también porque indirectamente se ejercería un cierto control municipal en sus actividades comerciales-, se concedía a los taberneros un plazo extendido hasta esa última fecha del dieciséis de abril para adecuar sus medidas con las del almotacén. De lo contrario, pagarían de sus bolsillos las tasas correspondientes a las ventas no sisadas ${ }^{40}$. Pero contrariamente a las previsiones, los impuestos sobre las bebidas alcohólicas ni estuvieron vigentes

Ibidem.

A.M.S.F., Varios: Iglesia. Leg 2.392.

40 A.M.S.F., Ibidem. 
diez años como disponía el real despacho, ni se aplicaron únicamente en la construcción de la nueva parroquia.

El obispo Valle había calculado cinco o seis años para la finalización de las obras, y así se lo comunicó al Consejo de Castilla ${ }^{41}$. Fernando VI, por su parte, superó con generosidad este plazo de tiempo pensado por el prelado para la ejecución de las obras de la iglesia y lo extendió hasta diez años. Pero ambas estimaciones fueron superadas por la realidad y la iglesia requirió el producto de los arbitrios para su total conclusión no diez, sino veinte años, es decir, de 1757 a 1777 . Por ello se hicieron necesarias dos prórrogas, la primera concedida por seis años a partir de $1767^{42}$ y la segunda, por cuatro, de 1773 a $1777^{43}$. Con todo, los impuestos no habrian de desaparacer en este último año, sino que continuarian en vigor oficialmente hasta 1818 , subsanando diversas necesidades. La primera de ellas - a partir de 1779 - fue dotar económicamente a la fábrica de la nueva parroquia, incapaz de conseguir los beneficios suficientes para cubrir los gastos del culto divino, a pesar del extraordinario - aunque ficticio- aumento de feligreses ${ }^{44}$. Por el mismo motivo, se otorgó una cantidad fija anual que sirviera para el mantenimiento de los ministros de la parroquia, quienes hasta ese momento habian carecido de ingreso fijo alguno ${ }^{45}$.

Por otro lado, el vino y el aguardiente sirvieron también para costear las urgentes reparaciones requeridas por esa nueva parroquia tan mal edificada, que empezó a amenazar ruina mediados los ochenta, a tan solo veinte años de su consagración. También fue conseguido con el producto de los arbitrios la construcción de un cementerio en terrenos de la iglesia - a espaldas del templo- con la intención de sustituir, por insuficiente, al cubículo usado para ese menester en los bajos del sacro edificio rebosante de cadáveres en el último decenio del siglo ${ }^{46}$. Fuera del terreno estrictamente parroquial - aunque relacionado de algún modo con la be-

4) A.D.C., Secretaría de Cámara. Leg. 22. Informe del obispo al Consejo del 13-XII-1756.

42 Ibidem. Decreto techado el 20-X11-1765.

43 A.M.S.F., Varios Iglesia. Leg. 2.392. Real Despacho fechado el 9-VIIl-1773.

44 A.D.C., Varios. Leg. 1.968, La aparente contradicción entre un notable aumento del número de asistentes a los actos religiosos y la pobreza de la parroquia se debió a que aquellos incluidos en la jurisdicción religiosa militar - la mayor y mejor parte de la población-abonaban en su parroquia castrense los derechos por bautizos, matrimonios, defunciones y demás funciones religiosas, pero preferian asistir a los actos de la parroquia diocesana, incrementándose así extraordinariamente los gastos sin aumentar los ingresos.

45 A.D.C., Secretaria de cámara. Leg. 32. Real Despacho fechado el 11-111-1779.

46 A.M.S.F., Varios: Iglesia. Leg. 2.393. Informes del arquitecto Torcuato Benjumeda y del mayordomo de la fábrica parroquial Antonio Martínez, ambos fechados en abril de 1796. 
neficiencia diocesana - los arbitrios sirvieron para sustentar económicamente a una muy nutrida Casa de la Misericordia en donde se acogia gran cantidad de niños y niñas huérfanos ${ }^{47}$. El fondo de las sisas fue usado asimismo en otros menesteres menos loables y más de carácter bancario. Por ejemplo, se empleó en la financiación del acondicionamiento de las vías del término municipal, adelantándose grandes sumas, reintegradas más tarde, como ocurrió en el año 1784, mientras se ponía en marcha una nueva carga fiscal sobre el vino y el aguardiente destinada a la reparación y mantenimiento de las carreteras ${ }^{48}$. El fondo del arbitrio hizo, incluso, de casa de cambio cuando la Marina necesitó la conversión de vales reales en dinero efectivo para la financiación de alguna campaña militar. El ayuntamiento, aceptando el trueque en obsequio del Real Servicio, perdió más de veinte mil reales en la operación, debido a la mala conversión de los vales ${ }^{49}$, con lo cual el depósito de los impuestos salió perjudicado. Más tarde, cuando llegaron las difíciles situaciones de la Guerra de la Independencia y las singulares circunstancias vividas por la Isla de León en ese tiempo, el arbitrio fue utilizado para socorrer a las tropas acantonadas en la Villa mientras se les encontraba acomodo ${ }^{50}$.

Era de esperar que un dinero de tan fácil entrada en arcas como el de los impuestos sobre las bebidas alcohólicas, pronto despertase la codicia humana, como en efecto sucedió. El alcalde mayor de la Isla de León, cuando no se había completado aún la obra de la nueva parroquia, convenció al obispo Tomás del Valle para que propusiera al Consejo de Castilla el reparto del ingreso de los arbitrios al cincuenta por ciento entre iglesia y ayuntamiento. Su petición se basaba en una supuesta urgencia para resolver ciertos asuntos pendientes en la villa, por lo cual había necesidad de esos fondos. El prelado, engañado por la «fiable» palabra del alcalde, o, quizá, demasiado astuto como para enfrentarse a la autoridad civil, así lo propuso al alto tribunal. Éste no aceptó la proposición en aras del contenido del despacho de concesión del arbitrio, cuyo producto había de ser exclusivamente upara las obras interiores y exteriores

47 A.D.C., Secretaría de cámara. Leg. 50. Real Despacho fechado el 30-III-1796. La idea de instalar un horfanato en la Isla de León la tuvo el presbítero Juan Evangelista Jiménez, teniente de cura de la parroquia diocesana. Ante los problemas financieros de la institución, el Consejo de Castilla aceptó el dotar con un real diario cada uno de los recogidos en la Casa de la Misericordia, con cargo al producto de las sisas sobre el vino y el aguardiente. La medida gubernamental provocó numerosas protestas.

48 A.M.S.F, Actas Capitulares. Libro 19. Sesión del 20-IV-1784.

49 Ibidem. Líbro 29. Sesión del 2-IV-1794.

so Ibidem. Libro 43. Sesión del 9-V-1808. El capitán general de la provincia dispuso que uel arbitrio y contribuciones sobre el vino y el aguardiente se reservara para el socorro de la tropam. 
de la iglesia». Pero ante la insistencia del obispo en el tema, el Consejo se vio obligado a dejar al descubierto las verdaderas intenciones del alcalde, quien "quería la mitad del arbitrio para aumentar su salario por habérsele privado de la percepción del derecho de licencias ${ }^{51}$. La pretensión, por tanto, no fue aprobada.

\section{EL PRODUCTO DE LOS ARBITRIOS}

Los arbitrios sobre el vino y el aguardiente, y compuestos, produjeron unos ingresos muy irregulares al estar directamente relacionados con las fluctuaciones del número de habitantes existentes en la Isla de León. De acuerdo con estas fluctuaciones, se pueden considerar dos períodos bien diferenciados: uno de crecimiento en las recaudaciones y otro de claro retraimiento. El primero está conexionado con el aumento de las cifras de los pobladores de la villa, por lo cual la llegada de los militares de la Armada, sus familiares y sirvientes y las de todos aquellos atraídos por el auge tomado por la Isla a raíz del traslado, incidieron en el espectacular ascenso del consumo de bebidas alcohólicas y, por tanto, de las sisas. En tal consumo no debemos olvidar al Ejército, y a sus tropas estacionadas en la isla temporalmente, como factor secundario, pero importante, en el incremento del producto de los impuestos. Esta dependencia entre los militares y el devenir económico de la isla se dejaría sentir también en los malos tiempos. Así, las sisas disminuirían sustancialmente en cuanto que la Marina y el país entraron en crisis una vez iniciado el siglo XIX.

El gráfico «A» nos da una visión completa del desarrollo de la racaudación de los dos arbitrios desde el año de su entrada en vigor, 1757 , hasta prácticamente su abolición definitiva en las cercanías del período constitucional del siglo xIx. La curva nos presenta, de modo indirecto, las diversas vicisitudes poblacionales, económicas y, en fin, históricas vividas por la Isla de León durante todo ese periodo de tiempo. Se observan claramente tres fases: una de escasos ingresos correspondiente a los primeros años de vida de los arbitrios (1757-1777); una segunda de consolidación y apogeo de los mismos (1778-1797) y una tercera de ocaso o decaimiento total, cuyo comienzo se sitúa en las proximidades del nefasto siglo decimonono (1798-1816).

El período 1757-1777 del gráfico es el correspondiente al tiempo durante el cual las sisas se destinaron exclusivamente a financiar la cons-

51 A.M.S.F., Varios: Iglesia. Leg. 2.392. Real Despacho fechado el 9-VIII-1773. 


\section{EL PRODUCTO DE LOS ARBITRIOS}

SOBRE EL VINO Y EL AGUARDIENTE

(1757-1816)

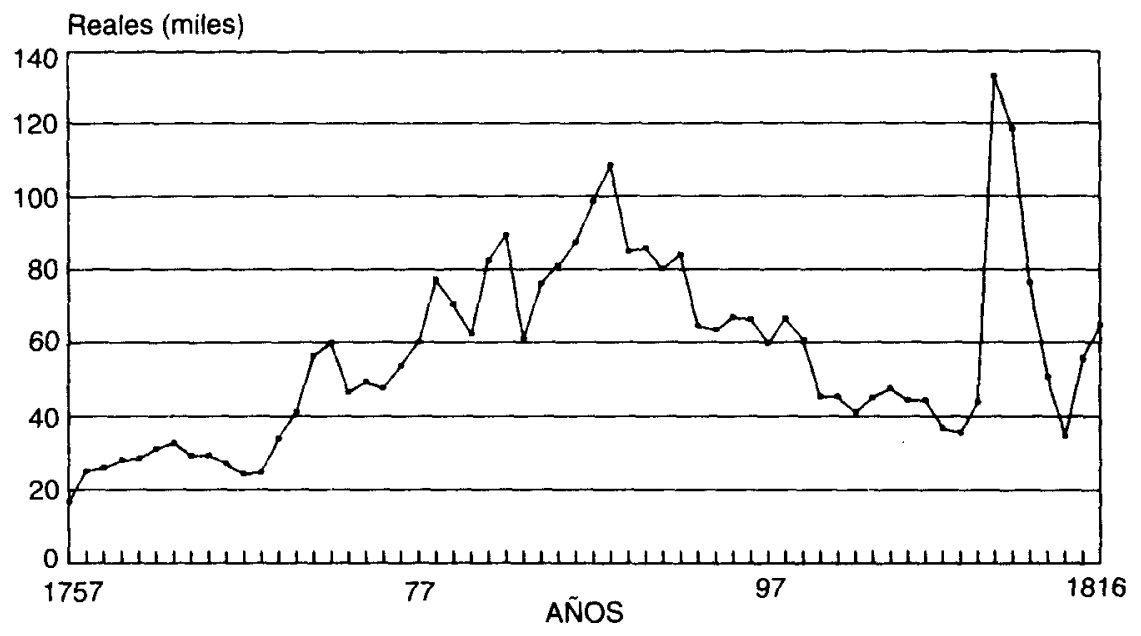

Producto anual

GRÁFICO A

Fuentes: A.M.S.F. Leg. 2392. Libros 1213. 1216

A.D.C. Leg. 1968

trucción de la nueva iglesia parroquial. En los once primeros años de vigencia de los arbitrios (1757-1768) el aumento poblacional de la isla, aunque importante respecto a la cifra de inicios del siglo, ha respondido solamente al proyecto de Ensenada sobre los arsenales militares. Son once años de estabilidad en la recaudación, y posiblemente en la población, en donde el producto de las sisas sobre las bebidas es el más bajo de toda la historia de los arbitrios. A partir del punto de inflexión positiva representado por el año sesenta y ocho, se produce un notable aumento en la recaudación, con una sostenida tendencia al alza hasta el final de este primer período considerado, 1777. Tres sucesos son los causantes de este espectacular incremento del producto de los arbitrios. El primero de ellos tiene su origen en el año 1769 con la llegada del Real Cuerpo de Marina, trasladado con casi todos sus hombres y dependencias de Cádiz -en donde estaba ubicado- a la Isla de León. Pero si los varios miles de hombres recién llegados a la isla, sin duda formidables consumidores de bebidas alcohólicas a la vista de los resultados, acrecientan el producto del arbitrio, la inesperada presencia de grandes contingentes 
de soldados del Ejército acantonados en la villa en el segundo semestre de 1770 con motivo de las tensiones generadas con Inglaterra a cuenta de las islas Malvinas, hizo subir aún más las cantidades producidas por las sisas que, por primera vez en su existencia, rozaron los sesenta mil reales de producto anual.

Retirados los soldados del Ejército, se produjo un lógico descenso en los arbitrios. A ello obedece el seno marcado por el año 1773, aunque pronto, en 1776, se vuelven a alcanzar las cotas de ingresos anteriores debido a la llegada de más tropas del Ejército, venidas esta vez, no para ser estacionadas temporalmente en la villa, sino para ser destinadas a engrosar los batallones de Marina, adonde habian sido transferidas. Es en ese momento cuando está a punto de iniciarse el que sería el período de apogeo tanto poblacional como económico de la Isla de León en el siglo XVIII. Sin lugar a dudas, el traslado de la Marina a la isla dio nueva vida a ésta $y$, por tanto, a los impuestos sobre el vino y el aguardiente. En total, desde el inicio de la imposición de las tasas sobre las bebidas alcohólicas en 1757 y hasta 1777 , las sisas produjeron en esos veinte años un total aproximado de 772.677 reales ${ }^{52}$.

El segundo período comenzado con el año setenta y ocho se estrenó con la llegada de nuevas tropas del Ejército también transferidas a los batallones de Marina y fue el más esplendoroso para la Isla de León en todo el siglo XVIII y, consecuentemente, para la historia de las sisas. La recaudación producida por los impuestos alcanzó, desde el año 1778 hasta 1797, una cantidad cercana al millón seiscientos mil reales de vellón ${ }^{53}$, lo cual ofrece una media anual de 77.578 reales. Ambas cifras serian las más altas de toda la vida del arbitrio. En efecto, de inmediato, a partir de 1779, se inicia un tramo ascendente producido por la enorme actividad desarrollada en la Isla de León con motivo de la Guerra de Gibraltar. Tanto el paso y estacionamiento de las tropas del Ejército, como la diligencia desplegada por la Marina con motivo de este conflicto con Inglaterra, provocaron un continuo fluir de gentes, uniformados o no, que aumentaron, como consecuencia, el consumo de alcohol. La paz firmada con el inglés en 1783 hizo descender considerablemente el producto de las sisas y de ahí la inflexión negativa de ese año. Pero es precisamente desde 1783 y hasta 1792 cuando el arbitrio vive su mejor época, coincidiendo

\footnotetext{
52 En el cómputo de las cantidades producidas por los arbitrios se han redondeado a reales y no se han tenido en cuenta, por tanto, los maravedís.

53 En concreto 1.551 .598 reales, aunque la cantidad no se pueda considerar definitiva al no existir en la documentación consultada datos de lo producido por el aguardiente en los meses de enero, febrero y marzo de los años 1780 y 1781.
} 
con el tiempo dorado de la villa en el cual todo parecía ir bien y sólo se respiraba prosperidad. La población había aumentado considerablemente $y$ en 1787 se sobrepasan los treinta mil habitantes ${ }^{54}$, en un desenfrenado crecimiento aparentemente sin final, alcanzándose en 1795 las más de cuarenta mil almas residentes en la Isla de León ${ }^{55}$. La producción industrial del Arsenal de la Carraca es indicativa de este período de bonanza isleña con la construcción de cinco fragatas entre 1779 y $1791^{56}$. En ese estado de ánimo, no pareció afectar demasiado a la villa un hecho de importantísimas consecuencias posteriores: la pérdida de jurisdicción sobre parte de su territorio al quedar segregada la considerada como «villa de exclusivo ámbito militar" del resto del pueblo, cuando fue creada la ciudad de San Carlos ${ }^{57}$. Esta medida afectó de inmediato a las bebidas alcohólicas expendidas dentro de la ciudad militar al quedar libres de las cargas impositivas de los arbitrios ${ }^{58}$. No obstante, el producto de las sisas no pareció acusar en demasía, al menos de momento, la nueva estructuración fiscal del territorio isleño y el ayuntamiento no otorgó gran importancia a la reducción del ámbito municipal de la villa. La euforia reinante en la isla y la gran entrada de capital en las arcas de los impuestos hacian olvidar todo lo demás.

El auge isleño pareció venirse abajo después de 1792. La guerra contra la convención francesa marcaría el principio del declive de la Isla de León, al igual que para España entera. Se inicia en 1793 un tiempo de guerras continuas, bien contra Francia, o Inglaterra, o para defenderse de la invasión napoleónica, que afectaría grandemente a la isla. Por ello, en ese año noventa y tres se observa el comienzo de un tramo de tendencia negativa en la recaudación de los arbitrios en directa relación con el descenso del número de militares presentes en la Isla y con la disminución de las actividades económicas, que mermarían notablemente en el período siguiente, 1798-1816.

Al conflicto armado contra la Revolución le sucedió casi inmediatamente otro en contra de Inglaterra, a todas luces demasiado prolongado

54 A.M.S.F., Varios: Iglesia. Cabildo del 1-VI-1787. Informaba el alcalde mayor sobre el número de habitantes de la Isla en 1787: «hoy, según el nuevo padrón ejecutado, se compone de 32.232 almas, sin los pasajeros y huéspedes, que no es éste el menor número».

55 Ponz, A., Viaje de España. Tomo XVII. Madrid 1988. En su visita a la zona gaditana en el último decenio del siglo, el autor cifraba en «cuarenta mil las almas de comunión, dando por supuesto que no entran párvulos ni transeúntes".

56 Caistelly, J., Opus cit., pág. 162.

57 TORREjón Chaves, J., El cuartel de batallones de la Nueva Población de San Carlos (17861794). Cádiz 1987.

${ }_{58}$ A.M.S.F., Varios: Iglesia. Leg. 2.392. Las bebidas expendidas en la jurisdicción de la Ciudad Militar de San Carlos quedaron libres de sisas a partir de 1787. 
para las endebles Arcas del Estado español. Ante la ruina de la Hacienda nacional, los marinos marchan de la isla y el arsenal inicia un período de inactividad industrial que duró medio siglo. Concluyendo el xVIII, la isla iniciaría una nefasta marcha atrás de la que no se podría recuperar hasta bien entrada la actual centuria. Para colmo, en el verano del mismo año en que comenzó el desgraciado siglo XIX, se declaró una epidemia de peste amarilla en Cádiz ${ }^{59}$, que, por la proximidad geográfica de la capital y el continuo trasiego de gentes entre ambas localidades, pasó pronto a la Villa, segando la vida de varios cientos de isleños en escasos meses ${ }^{60}$. Las muertes y la situación de la Marina explican la primera recesión de este período, coincidente con el año del cólera morbo. A partir de entonces, la recaudación del arbitrio sigue una marcha titubeante alrededor de los cuarenta mil reales anuales, situándose en 1808 en valores similares a los de los primeros veinte años de su existencia. El motivo de esta pobre entrada de caudales en las arcas del arbitrio lo podríamos encontrar en el progresivo y constante descenso de la población, pues las gentes habían iniciado el éxodo como consecuencia de la penuria económica de la zona gaditana -cuyo comercio había disminuido notablemente a causa de los bloqueos ingleses- pero también por la paralización de las actividades navales del Departamento Marítimo, sin medios para llevar a cabo alguna acción de importancia contra los británicos, peligrosamente cerca de Cádiz desde finales del XVIII. La isla, en tan directa relación con la Marina, sólo había comenzado a sufrir las consecuencias de la ruina española, viviéndola a la par del cuerpo militar gracias al cual había renacido.

A pesar de la decante situación, a la Villa le quedaba aún por vivir el momento más brillante de su historia. El avance del invasor francés hacia el sur llegó a convertir en poco tiempo a la isla y a Cádiz en la única zona de España Libre de militares galos. La llegada de los primeros refugiados que huian de las tropas napoleónicas ya hizo subir ligeramente la recaudación de los arbitrios en 1809. Con todo, el momento más extraordinario de la existencia de los impuestos se dio en el año siguiente, en 1810. En este año, con las tropas ocupantes al otro lado del puente Zuazo, se celebraron las primeras sesiones de las Cortes de Cádiz en la Isla de León ${ }^{61}$, al no aconsejar el estado sanitario de la capital, bajo otro

59 Iglesias Rodriguez, J.J., La epidemia gaditana de fiebre amarilla de 1800. Cádiz 1987, pág. 31.

60 A.P.S.P.S.P. (Archivo parroquial de San Pedro y San Pablo), Libro de defunciones de la epidemia de 1800. Libro 68. Entre septiembre de 1800 y marzo de 1801 fallecieron en la Isla de León un total de novecientas treinta y una persona a causa de la epidemia de fiebre amarilla.

61 La primer sesión de las Cortes de Cádiz se celebró en la Isla de León el 24 de septiembre de 1810 . 
brote de fiebre amarilla, su celebración en ella. La Real Villa, convertida así en capital de la nación, albergó a una ingente cantidad de personas entre políticos, eclesiásticos, aquellas personas deseosas de escapar de las consecuencias de ser dominadas por los franceses, las familias gaditanas huidas de la epidemia y, por supuesto, decenas de miles de militares. Como consecuencia, hubo de construirse gran cantidad de viviendas para dar albergue a tan heterogéna población accidental ${ }^{62}$. La isla comenzó así un brevísimo período de tres años -1810, 1811 y 1812durante los cuales un inusitado esplendor económico reinó en la Villa. El arbitrio, siempre espejo de la evolución de esa economía, llegó a producir 132.955 reales en el primer año citado, 118.495 en el segundo y 76.432 en el tercero. De los años que se comentan -de 1798 a 1816- solamente estos tres citados de las Cortes de Cádiz, supusieron el 26,5 por 100 del total de los 1.237 .743 reales, cantidad a la que ascendió la recaudación del impuesto en este período. Como a principios de 1811 se consideró que la situación sanitaria había dejado de ser peligrosa en la capital, todo el aparato político se trasladó a ella para continuar los trabajos de la que sería la primera constitución española. El consiguiente descenso de población provocó el lógico retraimiento del producto de las sisas.

Terminada la guerra, concluyeron también las vicisitudes extraordinarias que la Historia hizo vivir a la isla. Entonces, se volvió a la realidad anterior a 1810 y al arbitrio ofreció en 1814 el punto más bajo de todo este tercer lapso de tiempo. A la marcha de las gentes se unió la retirada de las tropas acantonadas y la reducción de los efectos navales. Aunque lo más grave, sin duda, fue la pérdida absoluta del poder adquisitivo de los marinos motivada por la ruina del Estado, incapaz de atender a los salarios de sus funcionarios. El síndico personero denunciaba acertadamente en 1816 este aspecto en dos intervenciones suyas ante el cabildo, exponiendo en la primera de ellas «...la miseria en que se halla este pueblo por el atraso de pagas de los individuos de Marina" ${ }^{63}$. Mientras que en la segunda, proponía la adopción de alguna solución al problema, recomendado: "para evitar la despoblación que debe experimentarse en esta ciudad por la falta de auxilio que le prestaba la Marina y Arsenal de la Carraca a quien debe su origen ... solicito la ampliación de su términon. ${ }^{64}$.

62 Madoz, P., Diccionario Geográfico-estadístico-histórico de España y sus posesiones de ultramar (1845-1850). Cádiz 1987.

63 A.M.S.F., Actas Capitulares. Libro 51. Sesión del 18-111-1816.

64 Ibidem. Sesión del 19-V-1816. 
A pesar de la recesión, los arbitrios parecieron recuperarse algo en los años $1815 \mathrm{y}$, especialmente, en 1816, aunque su tendencia a la baja quedó reafirmada por la cantidad obtenida en 1817. A partir de este último año los impuestos entrarían definitivamente en fase de extinción. Un Real Decreto fechado en enero de 1818, consecuente con la reforma fiscal de 1817 , ordenaba la suspensión de todos los arbitrios en la forma realizada hasta entonces, «recaudándose en lo sucesivo por aumento de la contribución general en el modo que previene el Real Decreto" ${ }^{65}$. Cesó de esta manera el llamado arbitrio de la carretera, nacido en 1784, y también, por supuesto, las sisas establecidas en 1757 sobre las bebidas alcohólicas, destinadas a la construcción de la iglesia y al mantenimiento de la parroquia y sus ministros. No obstante, el ayuntamiento isleño no quedó muy conforme con el contenido del Decreto en lo referente a los impuestos de la iglesia. Éstos habían sido instaurados con un Real Despacho específico sobre el asunto y los ediles seguían pensando en octubre de 1818 -nueve meses más tarde del Decreto de abolición- que mientras no se promulgase un documento del mismo rango y características al Despacho de 1757, la cancelación de los arbitrios no sería efectiva. Por tanto, decidieron reiniciar el proceso de reparto acostumbrado para volver a cobrar las sisas ${ }^{66}$. La inmediata respuesta del intendente dejó sin efecto la pretendida iniciativa municipal, al ordenar taxativamente el cese en el cobro del arbitrio de la iglesia ${ }^{67}$.

Después del trienio liberal -improductivo para el mantenimiento de iglesia y clero- se trató de restablecer las sisas, pero un recurso judicial presentado por el gremio de los montañeses abortó cualquier iniciativa al respecto ${ }^{68}$. Se habría de esperar al reinado de Isabel II y a su decreto de 1841 para que las iglesias y los cultos celebrados en ellas recibieran una atención económica establecida legalmente por medio de la Contribución de Culto y Clero ${ }^{69}$.

En sus sesenta años de vida, las sisas sobre el vino y el aguardiente y mistelas destinadas a la iglesia produjeron un total de 3.416 .801 reales ${ }^{70}$, debiéndose considerar esta cantidad por defecto a causa de dos motivos distintos. El primero, por carecerse, en ocasiones, de una información completa sobre el producto anual de los impuestos al faltar en

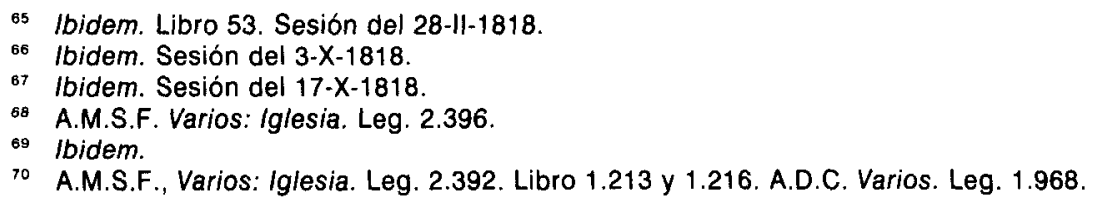


los documentos manejados la recaudación de algunos meses. Después, porque no se han incluido las rentas de las acciones de Banco de San Carlos y vales reales comprados con el capital acumulado en el fondo del arbitrio a partir de 1783 . Es decir, los casi tres millones y medio de reales se refieren exclusivamente al monto total de lo sisado del vino y del aguardiente entre 1757 y 1817. 